\title{
ON ELEMENTARY HEAVY PARTICLES WITH ANY INTEGRAL CHARGE: ERRATA
}

\author{
Bу H. J. ВнавнA, Ph.D.
}

(Vol XI, No. 4, April 1940, Section A, pp. 347-368)

The following misprints have occurred :-

The expression at the bottom of p. 354 should contain $c^{2}$ after $\triangle M$.

In the formula for $1 / \tau$ on p. 355 , line 8 read $\mathrm{g}^{2}$ instead of $\delta^{2}$.

In line 14, p. 356 , delete " so that $\left(\mathbf{p}_{f}, \mathbf{p}_{0}\right)=\cos \theta$."

The equation at the top of p. 358 should not be numbered (13).

In equation (17) read $d Q$ instead of $d \theta$, and $g_{2}^{\prime}$ instead of $g^{\prime}{ }_{1}$

In line 2, p. $360 \mathrm{read}(\mathrm{M} / \mu)^{2}$ instead of $(\mathrm{M} / \mathrm{m})^{2}$.

In line 1, p. 361 read (30) instead of (29).

The last word of the subtitle on p. 362 should be "Photons" not "Protons".

In the sentence immediately after (36) on p. 362 read "process" instead of " processes ", and "(35) or (36) " instead of " (35) and (36)"

In the last line before (37) insert " $\theta$ " between "direction" and "is".

in the first term in square brackets of $(40)$ read $c^{2} p^{2}$ instead of $p^{2}$ in the numerator and $(\Delta M c)^{2}$ instead of $(\Delta M)^{2}$ in the denominator.

In (44) read $e^{4}$ instead of $c^{4}$.

Equation (46) should read

$$
a l=\int_{\epsilon_{0}}^{\epsilon} \frac{d \epsilon^{\prime}}{\log \epsilon^{\prime}}=\overline{\mathrm{E} i}\left(\log _{\epsilon} \epsilon\right)-\overline{\mathbf{E}} i\left(\log _{\epsilon} \epsilon_{0}\right) .
$$

In line 5, p. 366 read " quarter" instead of " half".

In line 16, of the Summary on p. 367 read $10^{-25} \mathrm{~cm}^{2}$ instead of $10^{-27} \mathrm{~cm} .^{2}$

In line 3 , p. 368 read "track" instead of "tract". 